\section{I $\mathbf{B}$ A Institute of \\ YK Business Administration \\ तर Karachi \\ Leadership and Ideas for Tomorrow}

Article 2

Volume 1 Issue 1 July - December 2006

7-1-2006

\title{
Front Matter of Volume 1 Number 1
}

Danishmand .

Institute of Business Administration, Karachi, Pakistan

Follow this and additional works at: https://ir.iba.edu.pk/businessreview

Part of the Business Commons

c) (i)

This work is licensed under a Creative Commons Attribution 4.0 International License.

\section{Recommended Citation}

., D. (2006). Front Matter of Volume 1 Number 1. Business Review, 1(1), 2. Retrieved from https://doi.org/ 10.54784/1990-6587.1090

This article is brought to you by iRepository for open access under the Creative Commons Attribution 4.0 License and is available at https://ir.iba.edu.pk/businessreview/vol1/iss1/2. For more information, please contact irepository@iba.edu.pk. 
Volume 1 Number 1

\section{Business Review \\ July - December 2006}

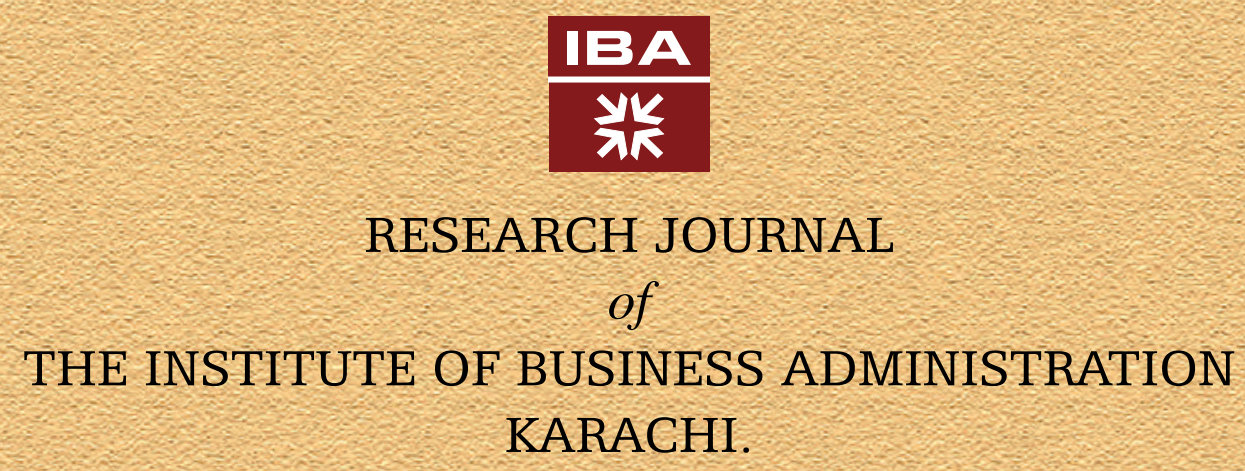


https://ir.iba.edu.pk/businessreview/vol1/iss1/2

DOI: https://doi.org/10.54784/1990-6587.1090

\section{Designed G Printed by}

\section{IIIBBCL}

BBCL House: 4-C, Khayaban-e-Tanzeem, DHA Phase 5, Karachi-75500, Pakistan.

Phones: (92-21) 5831361-64 Fax: (92-21) 5877659-60

Email: info@bbcl.org 


\section{Business Review}

\section{IEA} 率

RESEARCH JOURNAL

of

THE INSTITUTE OF BUSINESS ADMINISTRATION KARACHI. 


\title{
IEA 率 \\ Business Review
}

\author{
Editorial Board \\ Danishmand \\ Director \\ Institute of Business Administration \\ Chair \\ Tufail A. Qureshi \\ Editor \\ Aquila Ismail \\ Literary Editor
}

\section{Advisory Board}

Khadija Malik Bari

I.A. Mukhtar

Zeenat Ismail
Javed Hussain

Mirza Sardar Hussain

Naved Ahmad

\section{External Editors}

Talat A. Wazarat

Akif Hassan

Abdul Rashid

\section{Consulting Foreign Editors}

Nedzad S. Basic

Oscar T. Brookins

Bettina Robotka
John Donavan

John Q. Adams

Toshio Fujita

Khursheed Omer

D.U. Opata

S.W.S.B. Dasanayaka 


\section{CONTENTS}

Director,s Note.

Articles

Training Impact Analysis - Applying the modified combined model of Kirkpatrick "s and Phillips, Taining Evaluation to measure the Training Impact: Toshio Fujita

Socioeconomic Status as a Predictor of Marital Adjustment in Working Women: Zeenat Ismail, Kausar Ansari _ 29

Why do Firms Manage their Earnings?: Zeeshan Ahmed

Corporate Social Responsibility: Akbar Abdul Ali 58

Random Walk Tests for KSE-100 Index: Evidence and Implications: Abdul Rashid

Knowledge Entrepreneurship: A new Paradigm for Organizational Performance: S.M. Taha

Mechanisms Underlying the Phenomenon of Cluster Formation in the Textile/Apparel Industry in Pakistan: Khadija Bari

Language and the Structuring of the Intellect Towards the Realization of the Total Man: D.U. Opata

Discussions

Wavelet based SARIMA models for Forecasting Natural Gas Demand: S.M. Aqil Burney, Major Afzal Saleemi, Syed Akhter Raza

Perceptions and Attitudes of University-Going Young Adult Males about Metrosexuality fi An Exploratory Study: Farheen Faiyaz, Carissa P.S. D,, souza, Nasir Ahmed Syed

Influence of Foreign Media on Fashion in Young Adults in Pakistan: Arif Hasan, Shaza Bari

The Influence of Children on Family Purchase Decisions: A

Phenomenological Approach: Usman Majeed, Nadia S. Banoori

\section{Fact File}

Have we missed the rally?: Talib Haider

Why is a new index needed?: Shama Ahmed

Book Review

Barbara D. Metcalf, Islamic Contestations. Essays on Muslims in India and Pakistan: Bettina Robotka

About Our Authors 201

A Word About The IBA 205

Note for Contributors 


\section{I=A Institute of Y Business Administration Karachi

\section{DIRECTOR'S NOTE}

On behalf of the IBA community, I welcome you to the first issue of our Research Journal - The Business Review. As a multidisciplinary Journal, it cuts across various related disciplines being pursued at the Institute of Business Administration. It seeks to cover a wide range of issues in the areas of business, humanities, social and management sciences, administration and governance.

We at the IBA are inspired by Sigmund Freud's determination "to see things clearly. If we cannot see things clearly, we will at least see what the obscurities are." This is wonderful time for teaching and research in all related areas of business. The economy is growing. Increasingly all parts of the world are accessible gradually. Pakistan's economy is growing and is getting integrated into a global economic and intellectual system. These changes and trends have implications for everyone in our country. We feel we have a role to encourage efforts continuously to make business education more relevant and more effective. We have a responsibility also to encourage research and addition of knowledge about Pakistani business, industry and government working in all its various forms and to encourage application of the knowledge to our work.

We are committed to the highest values of truth, science and humanity and $I$ hope this Journal will reflect and will be guided by these ideals.

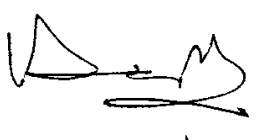

Danishmand

Director 


\section{Editorial Perspective}

$A$ distinguished landmark in the history of Pakistan's academic culture, the Institute of Business Administration, IBA, is more than an institution. It is a place for learning, teaching and research. Devoted to the pursuit of excellence, it symbolizes the perennial quest for ideas and ideals. The IBA is a diverse community of enquiring minds, seeking their relevance by creating knowledge through teaching and research.

At the IBA we are committed to the notion that teaching without research is a barren activity; devoid of creative joy and excitement. We also believe that research without transfer of knowledge is a concept without percept, formless and slight, blind and empty. BUSINESS REVIEW is an expression of such a well founded pedagogical experience, rooted in the research culture of the Institute of Business Administration.

Today, the unprecedented speed with which knowledge flows demands that to remain current and effective in our chosen field of vocation, we must creatively transcend the traditional academic boundaries and departmental isolation. Today, more than ever before, what was only a concept until yesterday is becoming a fast emerging reality. In the corporate world, "the knowledge society," as Drucker has pointed out, "will inevitably become far more competitive than any society we have yet known--- for the simple reason that with knowledge being universally accessible there are no excuses for non-performance."

Looking ahead into the future, the most important issue clearly recognized by those who are confronted with the challenges of the present day academic anxieties is to enlarge our exclusively defined departmental concerns and to broaden our orientation to make room for inter-disciplinary and inter-departmental research oriented teaching methodologies.

The incorporation of relevant ideas from related disciplines into our field of interest will contribute to finding answers to the issues pertaining to our own field of investigation. It will add new perspectives to our specialized competence.

Once the thought has found roots in our academic climate, it is believed that interdisciplinary research will broaden the spheres of our specialization. This hopeful thought is the assumption underlying the élan and the creative vivacity of all genuine research and teaching methodologies. It is characterized by the movement of an inquisitive mind into deeper learning experience. Our inter-departmental and interdisciplinary approach will make us see familiar things not only as they are and appear to be but also differently, as they are not but can be and therefore ought to be.

An institution of higher education is a community of the seekers of knowledge vying with each other and, in their own distinctively special ways, pursuing the ideal of excellence. The defining feature of such an educational institution is its research culture. Therefore, it's pedagogical and research orientation aims to benefit from 
various disciplines, to explore not only the content but also the processes underlying various issues. Research means exploration. Research oriented exploration deepens our perception of the underlying assumptions, beliefs and ideas, involved in our acts of decision making.

Therefore, no serious student of research can afford to ignore or disregard the role played by moral, ethical and religious biases in the determination of our decisions, judgments and choices. In the corporate world, the institutions primarily concerned with the control and management of human behavior, determine the contours of social 'facts' and corporate reality.

A Greek philosopher, Protagoras, is known to have famously observed that "reality has many faces." To draw this observation into the fold of research and education, let us maintain that the ultimate purpose of research is the dissemination of authentic and verifiable knowledge. Education facilitates the assimilation and incorporation of knowledge into our attitudes and the positions we take vis a vis life and the world.

"Reality", indeed, has many faces. Besides being multi-faceted, "Reality" is also a cobweb of relations and inter-relationships. Once it is touched somewhere, it begins to quiver everywhere. Reality resides in its appearances and it shows its real face only when its appearances have ceased to appear. Research and education tend to demolish our cherished illusions and ill founded notions, confronting us with the naked truth and stark reality.

Education and research are iconoclastic by nature; they do not hesitate to destroy, what Bacon called, the "idols of the mind". Reality, as it is in-itself rather than as it appears in and through its appearances, is the quest of all genuine research and of all teaching methodologies.

We live in a world which is not necessarily the best of all possible worlds. Through his creative will, his choices, decisions and evaluations, man can give his world whatever sense and meaning he can. The world of man is a world of his own making and for this he alone is responsible. We should not forget that the most sublime ethical values can be trivialized by moral opportunism and hollow pragmatism. Under the impact of the Sophists and the devastating expediency of their subjectivism, the Greek society disintegrated and, like ENRON, came tumbling down because of its flawed sense of moral integrity and the schizophrenic disregard for character ethics, resulting in the easy compulsion to legitimize moral flaws.

Obviously, our research in this area of utmost national concern implies an intensive inter-disciplinary approach to many subjects, especially education and particularly to the concepts of teaching and learning. Our research in these areas will deepen our realization of the importance of increased collaboration among various disciplines in order to design courses and teaching methodologies to incorporate emerging research into our own field of specialization. 
In nature and in life, reality is subservient to the law of change. "Only impermanence is permanence," said Heraclitus, a well-known exponent of Greek wisdom. Modern concept of the world, including the academic and the corporate world, is characterized by the notion of flux; it is a world constantly in the process of becoming. In such a world not only the context but also the perspectives continue to change. In life, one of the hardest things to achieve is to incorporate into our world-view the reality of change. The principle applies equally to our concepts of education, culture and research. There is something intrinsic and essential about such knowledge; it helps us understand the nature of "social reality" and, more importantly, the nature of "social facts". It is the kind of knowledge which reigns supreme in our corporate world. "For managers," says Drucker, "the dynamics of knowledge impose one clear imperative: every organization has to build the management of change into its very existence."

In research, the goal and the direction are inextricably intertwined. Research determines the direction in which we ought to be moving in order to approximate the goal of progress, development and growth. These two coordinates - the goal and the direction - are also the essential components of a creative and dynamic teaching methodology.

Therefore, as we move forward, we will be increasingly focused on the silent intimations of the future. And, directly in proportion to the level of our involvement and the strength of our commitment to the ideal of excellence, our research techniques will be guided by (1) the differential orientation and (2) the functionalist approach of the ideological components of our methodology. In other words, we will be moved, firstly, by the consideration of the difference our ideas make in our life, and, secondly, the instrumental value of our ideas in solving the problem we face as a consequence of our situated existence in the world. These two requirements define the essential nature of a philosophy of education. Teaching and research are its two fundamental features. Together they constitute the raison d'etre of an educational institution. We cannot celebrate teaching nor can we glorify it with the joy of doing the right job without a strong research bias. Research should indeed be the second nature to a teacher. Clearly there is an overlap in these orientations. Teaching aimed at enhancing the requirements of the learning process must accommodate a research perspective in order to add a creative dimension to the aims and objectives of education. To our philosophical outlook, we must also add a sociological perspective. A philosophy of education is rooted in the existing realities of a society. At any given stage of its development, each society is subject to its own inner laws of development and these laws determine the range and the extent within which social progress and personal refinement can take place. From a developmental perspective, to outline and to highlight these laws is the ultimate purpose of research.

Again, it is not in vain that we look up to education to divine for us the possibilities of what we are capable of becoming and hope that genuine research, pursued in earnest, will liberate us from the mistaken notions of future, destiny and fate, above all, the insidious and idolatoric assumptions, the unexamined and taken for granted beliefs. That is what serious research does and that is what teaching must do to merit the 
description of virtue it has always enjoyed because of its association with knowledge. So, in life, as in research, we will be guided not by the starry notions but by our rigorously examined beliefs and ideas and, more importantly, by our striving because in life man gets only what he strives for.

Education deepens our self-perception and the perception of the lived-world. Research lends meaning and significance to our situated existence. The "world concept", as an all inclusive category to which all the senses and meanings of the world belong, does not exist. Apart from the phenomenologically conceived world, i.e., apart from the lived-world or the worldliness of the world, there is no such thing as the world. The world does not exist, only the worlds exist, yours and mine, ours and theirs, scientific and technological, progressive and retrograde, corporate, commercial, industrial, cultural, moral, religious etc. Research and education remind us that we should not grieve the loss of an out-dated world; rather, we should celebrate the worldliness of our world, secure in the knowledge that in life nothing is permanent and nothing abides, every thing, including the future, is subject to change.

Research begins when a paradigm ceases to work and a world-view begins to show foundational stresses. It begins with a question we did not ask before, an assumption we failed to examine and a hypothesis we took for granted. It is then that we start searching for the answers we do not have, trying new ideas and different methods, making new assumptions, wanting to know what difference will they make in our lives and our world-view.

It is very important to stress that research presupposes a well defined methodology which lays down the foundations on which research ethos is built. By methodology we understand three things. Firstly, it means an inquiry into the kinds of evidence which are cited for or against a hypothesis. Secondly, it refers to the types of arguments which are used to establish a given hypothesis and, thirdly, a methodology embodies the issues which are taken as central during the course of research. These requirements can be effectively employed to guide, analyze and inform our methodology which, in order to serve our objective, must be practical rather than conceptual, comprising of both, thought and action. In research, especially in the field of education, this should be the overriding concern of our research methodology.

An educated man, like a student of research, is always an incomplete man, continuously reinventing himself, seeking his own fulfillment. Such men are irresistibly lured into novelty by the beckoning transcendence. Isac Casanbon has beautifully expressed the passion of an invincible researcher. "In research," he says, "the horizon recedes as we advance, and is no nearer at sixty than it was at twenty. As the power of endurance weakens with age the urgency of the pursuit grows more intense... And research is always incomplete." The life of a researcher is a trial by existence. Metaphorically, like a mirage, the search for truth keeps a thirsty man always on the move. Mr. Nixon, the late President of the United States, once observed that "a man is not finished when he is defeated; he is finished when he quits." Experience, especially the learning experience, does have consequences; it is fraught with existential implications. For 
our teaching practice and methodology, its relevance is directly proportional to the difference it makes in our life. With a change of paradigm and with each relevant learning experience, we acquire a new perspective on the world and on ourselves; experiencing ourselves and the world differently. When a paradigm changes, we do not see a different world; we see the same world differently.

Therefore, in designing our research methodologies, we must always be guided by two considerations. Firstly, we must never loose sight of the empirical teleology concerning the necessities which determine our vision of the possible. And, secondly, to do justice to our humanistic vision, our research orientation must be free from the necessity and determinism we uncritically take for granted. These two requirements are not identical, although they sound strikingly similar to each other. They refer to the "factual" and "theoretical" considerations which are involved in a given framework of research methodology. More importantly, they relate to the paradoxical nature of the "given" relationship between our paradigm and the "facts" we relate to support the paradigm. The requirement cannot be sustained meaningfully without a radically rigorous analysis of the nature and scope of the stipulated "relationship" itself. Bertrand Russell's admonition that "if the facts don't fit the theory, change the facts" does not make the paradox less paradoxical. In fact the lightness of his remark is almost unbearable. But that is the burden of all genuine research. It shows that in the field of natural sciences and also in the domain of humanities, the most compelling need for analysis and investigation arises when facts do not fit the theory and seemingly it appears as if no big task is really involved. However, a deeper examination reveals that the discrepancy and the incongruence is a consequence of our unexamined assumptions, the inadequacies inherent in our taken for granted attitude and the mistaken and dubious orientation of our methodologies. They raise serious research questions and we are caught in an either / or situation. Truth must either be sought everywhere or no where at all.

A teacher, seeking the knowledge in its "fullness", must, like a philosopher, see the life steadily and as a whole; seeing the world not only as it is but also as it can be and therefore ought to be. Like a phenomenologist, a researcher should avoid taking anything for granted, or committing himself to the unexamined knowledge claims. Pushing himself farther and farther still, standing at the threshold of the unknown, a scientist, a philosopher, a researcher, like a visionary, sees some thing which was always there, waiting to be discovered, wanting to be seen. That is the logic of discovery and the romance of research. Such is the story of teaching and the glory of education. $\mathrm{He}$, who is touched by this experience only once, is never the same person again. But, research, so understood, is not a solitary affair.

A mature and responsible research culture is a collective responsibility of an educated community, striving for creative self-expression, aspiring for excellence, experimenting with ideas, anxious to find out the difference they will make in our private and collective life. Research creates knowledge and only research based knowledge can teach our students the much desired lesson that they too can make a difference in their "portion 
of the world". An educated man, seeking the limit of critical thinking and the height of creative passion is seeking all the time his own self-realization and fulfillment, striving, at the same time, for collective excellence.

When research is conducted with such a passion and with the joy and excitement of creative will in the hope and anticipation of a dynamic future, through its interpretative compulsion it creates knowledge and experience. That is also the passion of a teacher and that is what creative thinking is all about. In the corporate world this is what learning organizations do all the time. 